\title{
Statistical Modeling for the Characteristics of Open Graded Friction Course Asphalt
}

\author{
Ola Abbas Al-Jawad \\ Shakir Al-Busaltan \\ Department of Civil Engineering, University of Kerbala, Karbala, Iraq \\ aljawadola@yahoo.com ‥f.al-busaltan@uokerbala.edu.iq
}

\author{
\begin{tabular}{|l|l|l|}
\hline Submission date:- 17/2/10/2019 & Acceptance date:- 13/3/2019 & Publication date:-6/4/2019
\end{tabular}
}

\begin{abstract}
An open-graded friction course (OGFC) is a special type surface layer of traditional Dense Graded Hot Mix Asphalts (DGHMA) pavement that is increasingly being used around the world due to its various benefits, such as, frictional, safety and environmental, etc. In this research, selective laboratory OGFC properties were statistically modeled depends on mix design inputs for two purposes or aims; mix inputs significant and prediction the OGFC properties according mix inputs. Principally, Indirect Tensile Strength (ITS), water sensitivity (TSR), and permeability (K) were selected from mechanical, durability, and volumetric properties, respectively as an output property; they represent the dependent variables for each model. While, fillers as conventional mineral filler or Ordinary Portland Cement (CMF, or OPC), binder content (BC), and polymer content (SBS) are represented inputs or the independent variables for all models. The generated models offered a vital achievable tool for prediction (e.g., their $\mathrm{R}^{2}$ are 0.781 , 0.821 and 0.820 , respectively, for the mentioned model's properties), also it helped to scale the significant of each independent variable (e.g., filler type significantly affect water sensitivity properties, its correlation was 0.752 ). This study reveals that the statistical modeling is achievable and offers a dynamic tool to describe the characteristics and performance of OGFC mixture in term volumetric, mechanical and durability properties.
\end{abstract}

Keywords: Asphalt concrete; Open Graded Friction Course; Polymer modified asphalt; Statistical analysis.

\section{Introduction.}

An open-graded friction course (OGFC) is a special type of asphalt mixtures which characterizes by using open-graded aggregate with high quality properties to ensure a mixture with an elevated connected air voids (AV) content and a course granular structure that improves high stone-on-stone contact. The mixture disintegration and resistance to permanent deformation are provided by stone-onstone contact of the course-aggregates fraction. Simultaneously, the air void skeleton forms by the coarse aggregates in a compacted specimens is partially occupied by portion of the fine-aggregate [1]. The structure of connected air void in the pavement provides high permeability and reduction in noise, which are directly classified as the main advantages provide by these mixtures when used as surface layer.

Splash and spray reduction help in: reducing wet skidding, reducing hydroplaning risk , and enhancing markings visibility of pavement in wet weather, which are all important advantages of OGFC mixtures [2][3]. Moreover, as compared to traditional Dense Graded Hot Mix Asphalts (DGHMA), the noise reduction effectiveness and riding quality are improved in this type of mixture [4][5]. Furthermore, cleaner runoff has been informed as one of the advantage of OGFC mixtures [6]. finally, smaller concentrations of pollutants related to particulate material and total suspended soils in the runoff gained from OGFC were reported by Several studies as compared to the traditional DGHMA [7][8].

On the other side, some challenges were informed when using OGFC and porous asphalt (PA) mixtures, i.e., mainly are decreased in the structural durability properties of the mixture such as resistance to disintegration and premature voids clogging for the functional durability properties [9][10], relatively high construction cost [9][11], use of limited high-quality materials, like aggregate, reduces structural contribution [12], and winter maintenance issues (e.g., black ice formation) [13]. 
Durability can identify as the resistance of the mixture to subsequent failures and distresses within the lifespan of the pavement layers under different loading and weather conditions. Raveling was reported as the most important distresses in OGFC in addition to the common distresses such as rutting (due to studded tires), reflective cracking, and delamination (which is principally caused by construction problems) [14].

Numerous causes for raveling development like hardening due to high rate of oxidation as a result of elevated air voids [15][16], deficiency in compaction [17], insufficient temperature during construction [18], and volumetric properties problems (e.g., incorrect calculation of binder content and/or air void content or lack of control of these properties during construction ) [19][20]. Numerous numerical and experimental models have been recommended to enhance understanding and predicting of raveling occurrence. The conclusion of these efforts is that raveling is mostly influenced by the total air voids content in the mixture and its binder content [21], however different parameters like the number of cold days at the project site and the course aggregate fraction also showed to influence both the appearance and magnitude of this distress [22] [23].

However, the main purpose of this study is to develop statistical models for predicting some volumetric, mechanical, and durability properties according to the variation in some main mix parameters. This prediction process could facilitate the understanding of the role of these parameters in general mix characteristics. Therefore, this paper will discuss the analysis process for built and validate the prospective models.

\section{Research materials and methodology.}

\subsection{Raw material.}

Limestone aggregates were supplied from local quarries, which is located to the west of Karbala. The physical properties of the aggregates present in Table (1). They were crushed limestone aggregate with a degree of crushing exceed 90\%. The ASTM D7064 proposed gradation range for OGFC and the middle range of each size was selected to prepare the mixes in this research work. Figure (1) displays the particle size distribution, which falls within the suggested lower and upper limits in ASTM D7064 gradation.

Table 1 Used aggregate physical properties.

\begin{tabular}{|l|c|c|}
\hline \multicolumn{1}{|c|}{ Measured properties } & Standard (ASTM) & Value \\
\hline Coarse Aggregate Bulk Specific Gravity (gr/cm3) & C127[24] & 2.591 \\
\hline Abrasion Value of Los Angeles (\%) & C131[25] & 21.5 \\
\hline Fine Aggregate Bulk Specific Gravity (gr/cm3) & C127[24] & 2.322 \\
\hline Coarse Aggregate Water Absorption (\%) & C127[24] & 2.22 \\
\hline Fine Aggregate Water Absorption (\%) & C127[24] & 2.41 \\
\hline One Side Fractured Particles \% & D5821[26] & 97.0 \\
\hline Two Sides Fractured Particles \% & D5821[26] & 95.0 \\
\hline
\end{tabular}

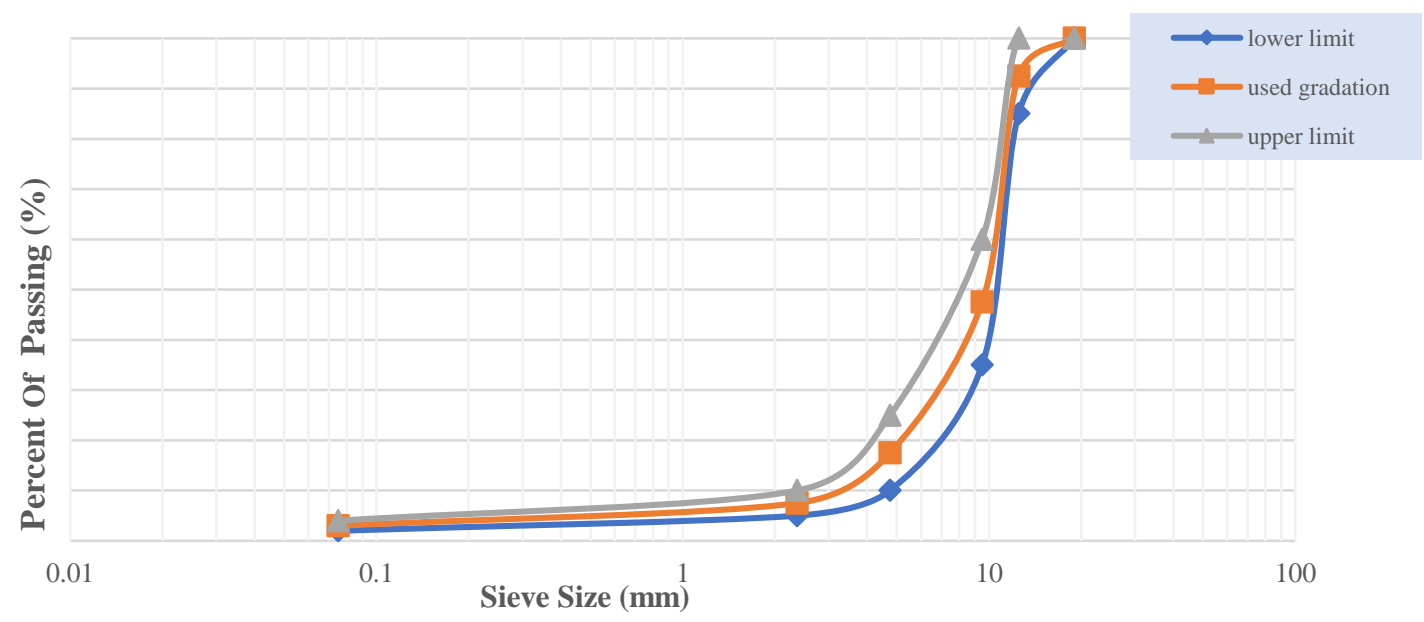


Figure 1 Particle size distribution of recommended range and used middle gradation[32] d nave a arrect enrect on mecnanical propertues ior me Uurc. I wo types or Inllers were usea in inıs research; namely, Ordinary Portland Cement (OPC), and Conventional Mineral Filler (CMF). Table (2) identifies physical and chemical properties for used fillers.

Table 2 The physical and chemical properties of OPC and CMF fillers.

\begin{tabular}{|c|c|c|}
\hline \multirow{2}{*}{ Property } & \multicolumn{2}{|c|}{ Physical } \\
\cline { 2 - 3 } & CMF & OPC \\
\hline surface Area $\left(\mathbf{m}^{\mathbf{2}} / \mathbf{k g}\right)$ & 223 & 345 \\
\hline Density $\left(\mathbf{g m} / \mathbf{c m}^{\mathbf{3}}\right)$ & 2.650 & 2.981 \\
\hline \multicolumn{2}{|c|}{ Chemical } \\
\hline $\mathbf{S i O}_{2}$ & 81.89 & 25.410 \\
\hline $\mathbf{A l}_{2} \mathbf{O}_{3}$ & 3.78 & 2.324 \\
\hline $\mathbf{F e}_{2} \mathbf{O}_{3}$ & 1.92 & 1.125 \\
\hline $\mathbf{C a O}^{\mathbf{M g O}}$ & 7.37 & 65.148 \\
\hline $\mathbf{K}_{2} \mathbf{O}$ & 3.45 & 1.326 \\
\hline $\mathbf{N a}_{2} \mathbf{O}$ & 0.73 & 0.760 \\
\hline & 0.19 & 1.714 \\
\hline
\end{tabular}

The used bitumen was nominated with penetration grade (40-50), it was supplied from AlNeasseria in the South of Iraq. The selected neat bitumen cement meet the specification in ASTM D946 [27]. Also, it was modified with SBS polymer called Kraton D1192 ESM. the properties of the neat and modified bitumen are presented in Table (3). while Table (4) illustrates the SBS polymer properties. The process of polymer-modified asphalts is not common procedure in Iraq. Thus, the SBS polymer and asphalt cement were prepared in the university of Kerbala laboratory.

Table 3 Properties of the neat and modified bitumen.

\begin{tabular}{|c|c|c|c|c|c|}
\hline Properties & Standard (ASTM) & OSBS & 2SBS & 4SBS & 6SBS \\
\hline $\begin{array}{c}\text { Penetration at } 25^{\circ} \mathrm{C} \\
(0.1 \mathrm{~mm})\end{array}$ & D5-73[28] & 41.47 & 2.5 & 2.1 & 1.87 \\
\hline $\begin{array}{c}\text { (Ring and ball) Softening } \\
\text { point }{ }^{\circ} \mathrm{C}\end{array}$ & C36-76 & 47.5 & 51 & 56 & 60.5 \\
\hline Ductility at $25^{\circ} \mathrm{C}(\mathrm{cm})$ & D113-79 & $>100 \mathrm{~cm}$ & $>100 \mathrm{~cm}$ & $80 \mathrm{~cm}$ & $76 \mathrm{~cm}$ \\
\hline P.I. & [29] & -2.23 & -2.30 & -1.56 & -0.79 \\
\hline \multicolumn{6}{|c|}{ AFTER thin-film oven test (TFOT) } \\
\hline $\begin{array}{c}\text { Penetration at } 25^{\circ} \mathrm{C} \\
(0.1 \mathrm{~mm})\end{array}$ & D5-73[30] & 2.90 & 2.38 & 2.00 & 1.8 \\
\hline $\begin{array}{c}\text { (Ring and ball) Softening } \\
\text { point }{ }^{\circ} \mathrm{C}\end{array}$ & C36-76 & 50.5 & 53 & 66.5 & 68 \\
\hline Mass Change, $\%$ & $\begin{array}{c}\text { D1754/D1754M - } 09 \\
\text { (Reapproved 2014) } \\
\text { Standard[31] }\end{array}$ & 0.03 & 0.01 & 0.00 & 0.00 \\
\hline
\end{tabular}


Table 4 Kraton D1192 ESM polymer properties.

\begin{tabular}{|c|c|c|c|}
\hline Property & Test Method & Unit & Tested Value \\
\hline Specific Gravity & SO 2781 & ---- & 0.94 \\
\hline Melt Flow Rate, $200^{\circ} \mathrm{C} / 5 \mathrm{~kg}$ & ISO 1133 & $\mathrm{~g} / 10 \mathrm{~min}$. & $<1$ \\
\hline Bulk Density & $\begin{array}{l}\text { ASTM D } 1895 \\
\text { method B }\end{array}$ & $\mathrm{kg} / \mathrm{dm}^{3}$ & 0.4 \\
\hline Hardness, Shore A $(15 \mathrm{sec})$ a & ASTM D 2240 & $\begin{array}{l}\text { Hardness, Shore A } \\
(15 \mathrm{sec})\end{array}$ & 70 \\
\hline $\begin{array}{l}\text { Apparent Molecular Mass of } \\
\text { Triblock }\end{array}$ & KM 01 & $\mathrm{~kg} / \mathrm{mol}$ & 150 \\
\hline Ash (ETM) & BAM 908 & $\% \mathrm{~W}$ & 5.0 \\
\hline Polystyrene Content & KM 03 & $\% \mathrm{~m}$ & 30.5 \\
\hline Triblock Content & KM 01 & $\%$ & 90 \\
\hline Vinyl Content & KM 03 & $\%$ & 35 \\
\hline Volatile Matter & KM 04 & $\% \mathrm{~m}$ & 0.3 \\
\hline Total Extractables & KM 05 & $\% \mathrm{~m}$ & 1.0 \\
\hline Antioxidant Content & KM 08 & $\% \mathrm{~m}$ & 0.16 \\
\hline Ash (ES, ET) & ISO 247 & $\% \mathrm{~m}$ & 0.25 \\
\hline Ash (ESM) & ISO 247 & $\% \mathrm{~m}$ & 3.75 \\
\hline
\end{tabular}

\subsection{Mixture design and analysis.}

Two OGFC mix types were included in this study i.e., traditional and modified mixes. The traditional mixture contained neat binder grade 40-50 type, virgin Coarse and fine aggregates, with CMF, OPC filler types. The selected of aggregate gradation was based on ASTM D7064[32] as cleared previously in Figure (1). Therefore, to determinate the characteristics of this mix, six different asphalt contents ranging between $5 \%-7.5 \%$ in increments of $0.5 \%$ is introduced. The bitumen contents $6 \%-7 \%$ were found, corresponding to best durability and volumetric properties that satisfy limitations of ASTM D7064 criteria; i.e., cantabro, air-voids, and draindown test results.

In this study, only three parameters where selected from mechanical, volumetric and durability properties to develop statistical models. However, the volumetric properties of OGFC mixes with twofiller types and four polymer content and six-asphalt content were characteristic. Main indexes like bulk density, air void, effective Porosity, VFB, and VMA, permeability, draindown, were determined and analyzed according to ASTM D7064[32], while the permeability was selected to represent the volumetric properties. The mechanical properties of OGFC were characterized by many tests; i.e., Indirect Tensile strength, Marshall Stability and flow, wheel truck test, skid resistance with the same mix design inputs. While, Indirect tensile strength (IDT) test according to AASHTO T283[33] was selected as an important test to represent the mechanical properties of the OGFC. Similarly, the durability properties were evaluated by tensile strength ratio (TSR) test according to AASHTO T283[33]. It is worth mentioned that in details models for each volumetric, mechanical, and durability properties will present in future publication.

\subsection{Collected Data.}

The input data (results) of permeability (as an average of four samples results), ITS (as an average of three samples results), and TSR (as an average of three set results) each set comprised two conditioned and unconditioned samples). A total of 639 test results were collected and analyzed in (SPSS) software to extract the averaged results which used to build the model, the input averaged data are as presented in Table (5) below:

Table 4 Results Matrix.

\begin{tabular}{|l|c|c|c|c|c|c|}
\hline \multirow{2}{*}{ Mix no. } & \multicolumn{3}{|c|}{ Mix design Input parameters } & \multicolumn{3}{|c|}{ Mix characteristic indexes } \\
\cline { 2 - 7 } & Filler type & SBS, \% & BC, \% & Permeability (K), cm/sec & ITS, KPa & TSR, \% \\
\hline P5MO-0 & OPC & 0 & 5 & 186.1 & 282.59 & 93.22 \\
\hline
\end{tabular}




\begin{tabular}{|c|c|c|c|c|c|c|}
\hline & OPC & 0 & 5 & 188.29 & ----- & ----- \\
\hline \multirow{2}{*}{ P5.5MO-0 } & OPC & 0 & 5.5 & 142.87 & 586.39 & 94.34 \\
\hline & OPC & 0 & 5.5 & 174.11 & ----- & ----- \\
\hline \multirow{4}{*}{ P6MO-0 } & OPC & 0 & 6 & 169.64 & 609.28 & 95.23 \\
\hline & OPC & 0 & 6 & 137.81 & ----- & ----- \\
\hline & OPC & 0 & 6 & 139.80 & ----- & ----- \\
\hline & OPC & 0 & 6 & 134.22 & ----- & ----- \\
\hline \multirow{5}{*}{ P6.5MC-0 } & CMF & 0 & 6.5 & ----- & 699.77 & 41.37 \\
\hline & CMF & 0 & 6.5 & ----- & 686.26 & 43.36 \\
\hline & CMF & 0 & 6.5 & ----- & 693.02 & 43.69 \\
\hline & CMF & 0 & 6.5 & ----- & ---- & 41.82 \\
\hline & CMF & 0 & 6.5 & ----- & ---- & 44.9 \\
\hline \multirow{7}{*}{ P6.5MO-0 } & OPC & 0 & 6.5 & 75.98 & 569.88 & 65.55 \\
\hline & OPC & 0 & 6.5 & 142.34 & 538.24 & 95.8 \\
\hline & OPC & 0 & 6.5 & 99.51 & 569.88 & 83.1 \\
\hline & OPC & 0 & 6.5 & 124.95 & 554.06 & 63.65 \\
\hline & OPC & 0 & 6.5 & 110.69 & ---- & 62.74 \\
\hline & OPC & 0 & 6.5 & 110.69 & ---- & 95.8 \\
\hline & OPC & 0 & 6.5 & 110.69 & ---- & ---- \\
\hline \multirow{7}{*}{ Р7MO-0 } & OPC & 0 & 7 & 103.05 & 537.19 & 94.12 \\
\hline & OPC & 0 & 7 & 103.05 & ---- & ---- \\
\hline & OPC & 0 & 7 & 77.21 & ---- & ---- \\
\hline & OPC & 0 & 7 & 83.57 & ---- & ---- \\
\hline & OPC & 0 & 7 & 103.05 & ---- & ---- \\
\hline & OPC & 0 & 7 & 103.04 & ---- & ---- \\
\hline & OPC & 0 & 7 & 103.05 & ---- & ---- \\
\hline \multirow{3}{*}{ P7.5MO-0 } & OPC & 0 & 7.5 & 106.72 & 290.71 & 93.01 \\
\hline & OPC & 0 & 7.5 & 100.17 & ---- & ---- \\
\hline & OPC & 0 & 7.5 & 103.44 & ---- & ---- \\
\hline \multirow{3}{*}{ P6MO-2 } & OPC & 2 & 6 & 213.6 & ---- & ---- \\
\hline & OPC & 2 & 6 & 251.75 & ---- & ---- \\
\hline & OPC & 2 & 6 & 180.6 & ---- & ---- \\
\hline \multirow{5}{*}{ P6.5MO-2 } & OPC & 2 & 6.5 & 188.69 & 823.99 & 95.1 \\
\hline & OPC & 2 & 6.5 & 209.16 & 709.54 & 89 \\
\hline & OPC & 2 & 6.5 & 232.79 & 759.49 & 94.99 \\
\hline & OPC & 2 & 6.5 & 174.77 & 701.88 & 87.5 \\
\hline & OPC & 2 & 6.5 & 200.58 & 734.52 & 95.6 \\
\hline \multirow{4}{*}{ P6.5MC-2 } & CMF & 2 & 6.5 & 202.72 & 679.66 & 76.6 \\
\hline & CMF & 2 & 6.5 & 219.59 & 627.71 & 76.25 \\
\hline & CMF & 2 & 6.5 & 211.15 & 680.85 & 74 \\
\hline & CMF & 2 & 6.5 & ---- & 768.25 & 73.88 \\
\hline
\end{tabular}




\begin{tabular}{|c|c|c|c|c|c|c|}
\hline & CMF & 2 & 6.5 & ---- & 654.28 & 74.12 \\
\hline \multirow{4}{*}{ P7MO-2 } & OPC & 2 & 7 & 162.52 & --- & ---- \\
\hline & OPC & 2 & 7 & 186.48 & ---- & ---- \\
\hline & OPC & 2 & 7 & 168.51 & ---- & ---- \\
\hline & OPC & 2 & 7 & 184.95 & ---- & ---- \\
\hline \multirow{5}{*}{ P6.5MO-4 } & OPC & 4 & 6.5 & 152.88 & 715.03 & 93.1 \\
\hline & OPC & 4 & 6.5 & 158.74 & 707.52 & 88.6 \\
\hline & OPC & 4 & 6.5 & 153.77 & 627.02 & 93.05 \\
\hline & OPC & 4 & 6.5 & 136.45 & 677.62 & 91.11 \\
\hline & OPC & 4 & 6.5 & 150.46 & ---- & ---- \\
\hline \multirow{5}{*}{ P6.5MC-4 } & CMF & 4 & 6.5 & 296.8 & 627.36 & 68.06 \\
\hline & CMF & 4 & 6.5 & 247.51 & 657.64 & 67.11 \\
\hline & CMF & 4 & 6.5 & 223.17 & 783.25 & 66.46 \\
\hline & CMF & 4 & 6.5 & 282.04 & 719.61 & 67.21 \\
\hline & CMF & 4 & 6.5 & 262.38 & 720.45 & ---- \\
\hline \multirow{5}{*}{ P6MO-4 } & OPC & 4 & 6 & 182.73 & 610.3 & ---- \\
\hline & OPC & 4 & 6 & 184.01 & 667.27 & ---- \\
\hline & OPC & 4 & 6 & 171.42 & ---- & ---- \\
\hline & OPC & 4 & 6 & 168.83 & ---- & ---- \\
\hline & OPC & 4 & 6 & 206.64 & ---- & ---- \\
\hline \multirow{3}{*}{ P6.5MC-6 } & CMF & 6 & 6.5 & 251.96 & 819.94 & 50.91 \\
\hline & $\mathrm{CMF}$ & 6 & 6.5 & 218.28 & ---- & 50.91 \\
\hline & CMF & 6 & 6.5 & 235.12 & ---- & 43.4 \\
\hline \multirow{4}{*}{ P6.5MO-6 } & OPC & 6 & 6.5 & 145.46 & 779.96 & 76.8 \\
\hline & OPC & 6 & 6.5 & 141.85 & 803.72 & 78.3 \\
\hline & OPC & 6 & 6.5 & 143.97 & 791.84 & 77.5 \\
\hline & OPC & 6 & 6.5 & 130.62 & ---- & ---- \\
\hline \multirow{4}{*}{ P7MO-4 } & OPC & 4 & 7 & 162.15 & ---- & ---- \\
\hline & OPC & 4 & 7 & 167.85 & ----- & ---- \\
\hline & OPC & 4 & 7 & 129.99 & ---- & ---- \\
\hline & OPC & 4 & 7 & 115.65 & ---- & ---- \\
\hline \multirow{5}{*}{ Р6МО-6 } & OPC & 6 & 6 & 178.25 & ---- & ---- \\
\hline & OPC & 6 & 6 & 205 & ---- & ---- \\
\hline & OPC & 6 & 6 & 225.82 & ---- & ---- \\
\hline & OPC & 6 & 6 & 195.55 & ---- & ---- \\
\hline & OPC & 6 & 6 & 173.11 & --- & ---- \\
\hline \multirow{2}{*}{ Р7МO-6 } & OPC & 6 & 7 & 105.18 & ---- & ---- \\
\hline & OPC & 6 & 7 & 107.58 & ---- & ---- \\
\hline
\end{tabular}




\section{Statistical analysis model.}

\subsection{Model preparation.}

Model preparation from the outcomes that obtained in the experimental work is an essential in this research. Empirical modeling was achieved using analysis tools of SPSS software. The variables involved in the empirical modeling were filler types, binder content, and percent of SBS. The collected averaged results are 72,40 , and 37 for each test of permeability, tensile strength ratio, and indirect tensile strength, respectively, consequently, a total of 639 test result were collected and analysis. The results were divided randomly into 49,30, 28 result to generate the model and the other 23, 10, 9 for each test of permeability, TSR, and ITS, respectively, were used to validate the model. The first step to model preparations is to the correlation between the variables using SPSS Pearson's correlation. Many combinations of variables were used starting from only constant to quadratic form of the variables with the incorporation of multiple terms of the various variables discussed above.

To achieve the obligations for the built models, program testing needs to determine dependent and independent variables of the developed models. The variables and the code adopted for calculation are presented in Table (6).

Table 5 Dependent and independent variables considered in regression analysis.

\begin{tabular}{|c|c|c|c|}
\hline \multicolumn{5}{|c|}{ Dependent variable } \\
\hline Abbrev. & Descrip. & Unit & Coded values \\
\hline ITS & Indirect tensile strength & $\mathrm{KPa}$ & \\
\hline $\boldsymbol{K}$ & permeability & $\%$ & \\
\hline $\boldsymbol{T S R}$ & Water sensitivity & 15 \\
\hline \multicolumn{5}{|c|}{ Independent variable } \\
\hline FT & Filler type & CMF & \\
\hline SBS & Polymer content & $\%$ & \\
\hline $\boldsymbol{B C}$ & Binder content & $\%$ & \\
\hline
\end{tabular}

\section{Result and Discussion for The Prediction Models.}

SPSS software was used to build and analysis the models. For the simplification the linear models were tried first, unfortunately, the trials that made for linear models were unsuccessful to represent the observations. However, it was found that all prediction models were nonlinear, as will see hereafter.

\subsection{Building the permeability model.}

As mentioned previously the Permeability was selected to build a model from many volumetric parameters. This selection is established on the believe that it is the most important character. Modeling permeability to filler type, binder content, and polymer content was conducted. Many models were tried (linear, multiple and nonlinear models). It was observed that all linear models were failed to estimate accurate predicted values of permeability. Tables (7) demonstrates samples of the tried models, whereas low values of $\left(\mathrm{R}^{2}\right)$ are the predominant for both regression and model validation. It is worth mentioned that other testing parameters than $\mathrm{R}^{2}$ were conducted to test the validity of the models, but the values of $\mathrm{R}^{2}$ are only presented for simplification and prevent dilatation.

On the other hand, after many trials a nonlinear model was determined with reasonable accuracy. The analysis results of adopted nonlinear model is shown in Tables (8), (9), and (10). The model's analysis consists of the analysis of goodness fitting and variance for observed and predicted result. The model adequacy is illustrated in figure (2). The following can be recognized from the analysis process:

1. Table (8) explains the bivariate Pearson Correlation between variables. The same table shows that the independent variables have very low to absent of correlation between each other, which is good for the accuracy of the model.

2. Table (8) demonstrates that the filler type has the most significant correlation to permeability, then binder content and lastly polymer content. Although, binder content is believed to be the most important, but we have to remember that the used ranges of building the model is limited.

3. Table (10) states that the MSE is low, which is good for the significant of the model. 
4. Table (9) shows the parameter of the developed model and its limitation with Confidence Interval of $95 \%$.

5. Table (10) discloses that the sum of regression is higher that sum of residue which is sustained the significant of the model. While, from the same table, the high value of the R-Square $(0.781)$ indicates an acceptable prediction.

6. Figure (2) indicates that acceptable scatter can recognized between predicted and observed $\mathrm{K}$ values, furthermore, almost all value within the significant level boundaries.

Table 6 Trial Equations to Predict The Value of Permeability.

\begin{tabular}{|c|c|c|}
\hline Types of equations & models & $\boldsymbol{R}^{\mathbf{2}}$ \\
\hline linear & $k=717.7+5.71 * s b s-16.3 * f t-39.4 * b c$ & 0.621 \\
\hline linear & $k=507.3-17.8 * f t$ & 0.401 \\
\hline cubic & $k=507.3-17.7 * f t$ & 0.401 \\
\hline compound & $k=1042.2+0.907 * f t$ & 0.311 \\
\hline logarithmic & $k=24223.4-1.7 * \ln f t$ & 0.311 \\
\hline nonlinear & $k=147.8+0.056 * s b s * f t * b c$ & 0.095 \\
\hline nonlinear & $k=145.88+2.6 *\left(\frac{s b s * f t}{L}\right)$ & 0.12 \\
\hline nonlinear & $k=306.8+0.486 * s b s^{2}-0.003 * f t^{3} * b c$ & 0.553 \\
\hline nonlinear & $\mathrm{K}=435.6=0.908 * \mathrm{sbs}^{*} \mathrm{bc}-2.29 * \mathrm{ft} * \mathrm{bc}$ & 0.612 \\
\hline
\end{tabular}

Table 7 Correlation Between Permeability and Variables.

\begin{tabular}{|c|c|c|c|c|c|}
\hline \multicolumn{6}{|c|}{ Correlations } \\
\hline & & $S B S$ & $F T$ & $B C$ & $K$ \\
\hline \multirow{3}{*}{$S B S$} & Pearson Correlation & 1 & -.205 & .038 & $.276 *$ \\
\hline & Sig. (2-tailed) & & .077 & .744 & .017 \\
\hline & No. & 75 & 75 & 75 & 75 \\
\hline \multirow{3}{*}{$F T$} & Pearson Correlation & -.205 & 1 & -.017 & $-.631 * *$ \\
\hline & Sig. (2-tailed) & .077 & & .886 & .000 \\
\hline & No. & 75 & 75 & 75 & 75 \\
\hline \multirow{3}{*}{$B C$} & Pearson Correlation & .038 & -.017 & 1 & $-.396 * *$ \\
\hline & Sig. (2-tailed) & .744 & .886 & & .000 \\
\hline & No. & 75 & 75 & 75 & 75 \\
\hline \multirow{3}{*}{$K$} & Pearson Correlation & $.276 *$ & $-.631 * *$ & $.396 * *$ & 1 \\
\hline & Sig. (2-tailed) & .017 & .000 & .000 & \\
\hline & No. & 75 & 75 & 75 & 75 \\
\hline
\end{tabular}

Table 8 Nonlinear permeability modeling

\begin{tabular}{|c|c|c|c|c|}
\hline $\begin{array}{c}\text { Developed } \\
\text { model }\end{array}$ & \multirow{5}{*}{$K=c 1+c 2 * B C+c 3 * B C^{2}+c 4 * S B S-c 5 * S B S^{2}+c 6 * S B S^{3}-c 7 * F T$} \\
\hline \multicolumn{4}{|c|}{ Parameter Estim. } \\
\cline { 4 - 5 } Parameter & Estim. & Std. Err. & Lower Bound. & Upper Bound. \\
\cline { 4 - 5 } & & 345.026 & 421.658 & 1798.634 \\
\hline $\boldsymbol{c 1}$ & 1110.146 & -43.951 & 383.198 \\
\hline $\boldsymbol{c} \mathbf{c}$ & 169.623 & 107.030 & -6.966 & 26.531 \\
\hline $\boldsymbol{c 3}$ & 9.783 & 8.393 & 11.572 & 32.547 \\
\hline $\boldsymbol{c 5}$ & 22.059 & 5.256 & .697 & 2.975 \\
\hline $\boldsymbol{c 6}$ & 1.836 & .571 & 11.810 & 18.742 \\
\hline $\boldsymbol{c 7}$ & 15.276 & 1.737 & 47.059 & 95.283 \\
\hline $\boldsymbol{c 4}$ & 71.171 & 12.083 & & \\
\hline
\end{tabular}


Table 9 ANOVA for permeability modeling

\begin{tabular}{|c|c|c|c|}
\hline \multicolumn{4}{|c|}{ ANOVAa } \\
\hline Source & Sum of Squares & $d f$ & Mean Squares \\
\hline Regression & 2149248.823 & 7 & 307035.546 \\
\hline Residual & 43006.629 & 68 & 632.450 \\
\hline Uncorrected Total & 2192255.452 & 75 & 74 \\
\hline Corrected Total & 195946.010 & Dep. variable: K \\
\hline \multicolumn{4}{|c|}{ (Residual Sum of Squares) /(Corrected Sum of Squares) $=.781}$. \\
\hline
\end{tabular}

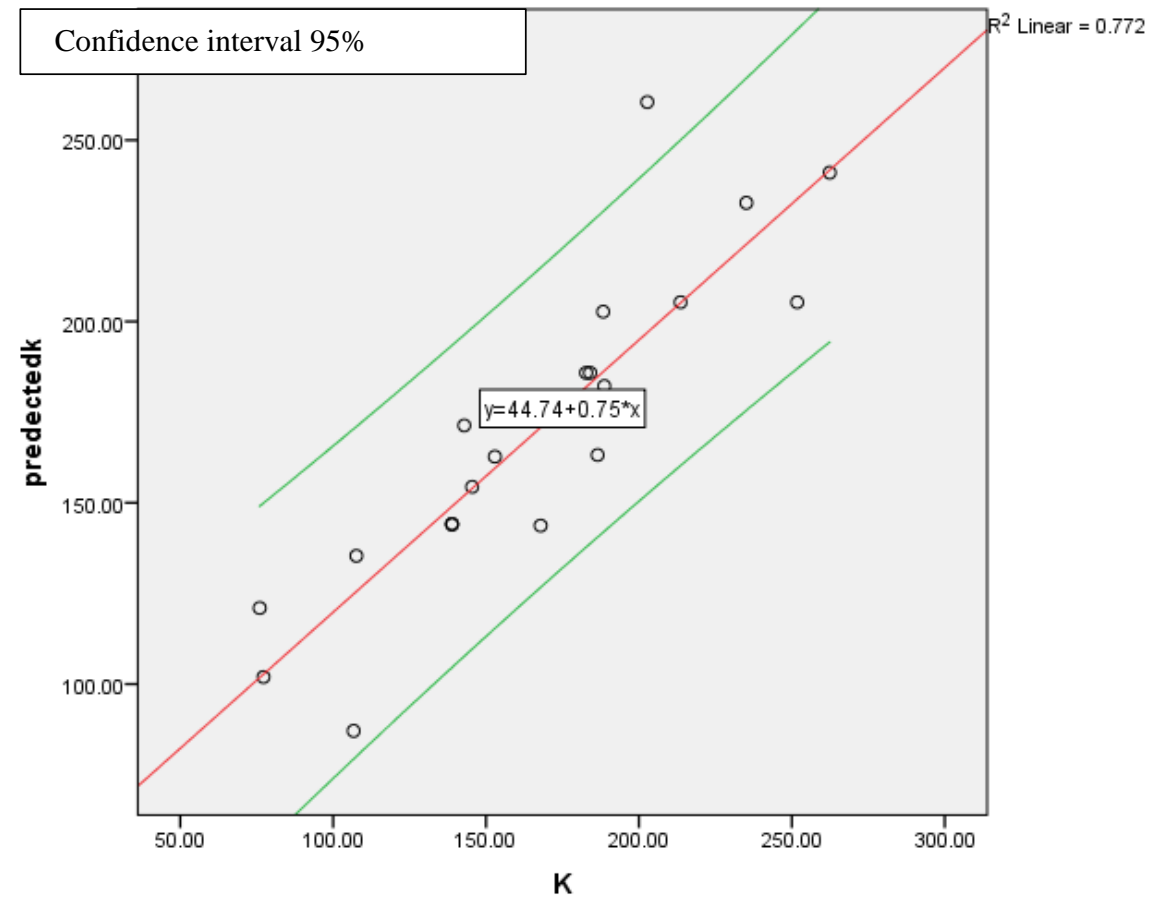

Figure 2comparisons between the experimental and predicted values of permeability.

\subsection{Building the Tensile strength ratio modal.}

As mentioned previously the TSR was selected to build a model from many durability parameters. This selection is established on the believe that it is the most important durability character. Modeling TSR to filler type, binder content, and polymer content was conducted. Many models were tried (linear, multiple and nonlinear models). It was observed that all linear models were failed to estimate accurate predicted values of TSR. Tables (11) demonstrates samples of the tried models, whereas low values of $\left(\mathrm{R}^{2}\right)$ are the predominant for both regression and model validation. It is worth mentioned that other testing parameters than $\mathrm{R}^{2}$ were used to test the validity of the models, but the values of $\mathrm{R}^{2}$ are only presented for simplification and prevent dilatation.

On the other hand, after many trials a nonlinear model was determined with reasonable accuracy. The analysis results of adopted nonlinear model are shown in Tables (12), (13), and (14). The model's analysis consists of the analysis of goodness fitting and variance for observed and predicted result. Figure (3) demonstrates the adequacy of model. The following can be recognized from the analysis process:

1. Table (12) explains the bivariate Pearson Correlation between variables. The same table shows that the independent variables have very low to absent of correlation between each other, which is good for the accuracy of the model.

2. Table (12) demonstrates that the filler type has the most significant correlation to TSR, then polymer content and lastly binder content. 
3. Table (14) states that the MSE is low, which is good for the significant of the model.

4. Table (13) shows the parameter of the developed model and its limitation with Confidence Interval of $95 \%$.

5. Table (14) discloses that the sum of regression is higher that sum of residue which is sustained the significant of the model. While, from the same table, the high value of the R-Square (0.821) indicates a good prediction, thus from this value a conclusion can draw that the developed model for Tensile strength ratio is acceptable.

6. Figure (3) indicates that acceptable scatter can recognized between predicted and observed operability values, furthermore, almost all value within the significant level boundaries.

Table 10 Trial Equations to Predict The Value of Tensile strength ratio.

\begin{tabular}{|c|c|c|}
\hline Types of equations & Models & $\boldsymbol{R}^{\mathbf{2}}$ \\
\hline Linear & $T S R=-7.9-0.024 * s b s-2.33 * b c+5.52 * f t$ & 0.569 \\
\hline Linear & $T S R-24.5+5.57 * f t$ & 0.566 \\
\hline Cubic & $T S R=23.25+0.159 * \mathrm{ft}^{2}$ & 0.566 \\
\hline Compound & $T S R=16.967+1.09 * f t$ & 0.536 \\
\hline Logarithmic & $T S R=1.25+1.41 * \ln f t$ & 0.536 \\
\hline Nonlinear & $T S R=115.3+0.002 * s b s * f t-6.339 * b c$ & 0.014 \\
\hline Nonlinear & $T S R=33.6-1.6 * 10^{-11} * f t^{2} * s b s^{5} * b c+0.008 * b c^{3} * f t$ & 0.245 \\
\hline Nonlinear & $T S R-8.176-0.003 * f t * s b s+0.733 * b c * f t$ & 0.451 \\
\hline Nonlinear & $T S R=-7.9-0.024 * s b s-2.33 * b c+5.52 * f t$ & 0.569 \\
\hline
\end{tabular}

Table 11 correlation between TSR and variables.

\begin{tabular}{|c|c|c|c|c|c|}
\hline \multicolumn{6}{|c|}{ Correlations } \\
\hline & & $T S R$ & $s b s$ & $B C$ & $F T$ \\
\hline \multirow{3}{*}{$T S R$} & Pearson Correlation & 1 & -.128 & -.116 & $.752 * *$ \\
\hline & Sig. (2-tailed) & & .430 & .476 & .000 \\
\hline & No. & 40 & 40 & 40 & 40 \\
\hline \multirow{3}{*}{$s b s$} & Pearson Correlation & -.128 & 1 & .097 & -.135 \\
\hline & Sig. (2-tailed) & .430 & & .550 & .407 \\
\hline & No. & 40 & 40 & 40 & 40 \\
\hline \multirow{3}{*}{$B C$} & Pearson Correlation & -.116 & .097 & 1 & -.094 \\
\hline & Sig. (2-tailed) & .476 & .550 & & .564 \\
\hline & No. & 40 & 40 & 40 & 40 \\
\hline \multirow{3}{*}{$F T$} & Pearson Correlation & $.752 * *$ & -.135 & -.094 & 1 \\
\hline & Sig. (2-tailed) & .000 & .407 & .564 & \\
\hline & No. & 40 & 40 & 40 & 40 \\
\hline
\end{tabular}

Table 12 Nonlinear TSR modeling

\begin{tabular}{|c|c|c|c|c|}
\hline \multirow{2}{*}{$\begin{array}{c}\text { Developed } \\
\text { model }\end{array}$} & \multicolumn{2}{|c|}{$T S R=c 1+c 2 * s b s-c 3 * s b s^{2}+c 4 * s b s^{3}-c 5 * b c+c 6 * b c^{3}+c 7 * F T$} \\
\hline \multicolumn{2}{|c|}{} & \multicolumn{3}{|c|}{ Parameter Estim. } \\
\hline \multirow{2}{*}{ Parameter } & Estim. & Std. Err. & \multicolumn{2}{c|}{$95 \%$ Confidence Interval } \\
\cline { 3 - 5 } & 262.594 & 114.196 & Lower Bound. & Upper Bound. \\
\hline$c 1$ & 5.940 & 1.442 & 30.260 & 494.927 \\
\hline$c 2$ & .158 & .048 & 3.007 & .873 \\
\hline$c 3$ & .001 & .000 & .060 & .002 \\
\hline$c 4$ & 80.307 & 27.208 & .000 & 135.662 \\
\hline$c 5$ & .655 & .232 & 24.952 & 1.126 \\
\hline$c 6$ & 5.607 & .567 & .183 & 6.761 \\
\hline$c 7$ & & & 4.454 & \\
\hline
\end{tabular}


Table 13 ANOVA for TSR modeling

\begin{tabular}{|c|c|c|c|}
\hline \multicolumn{5}{|c|}{ ANOVAa } \\
\hline Source & Sum of Squares & $d f$ & Mean Squares \\
\hline Regression & 236488.154 & 7 & 33784.022 \\
\hline Residual & 2393.275 & 33 & 72.523 \\
\hline Uncorrected Total & 238881.429 & 40 & 39 \\
\hline Corrected Total & 13398.602 & Dep. variable: TSR \\
\hline \multicolumn{4}{|c|}{} \\
\hline \multicolumn{4}{|c|}{ R squared $=1$ - (Residual Sum of Squares) /(Corrected Sum of Squares) $=.821}$. \\
\hline
\end{tabular}

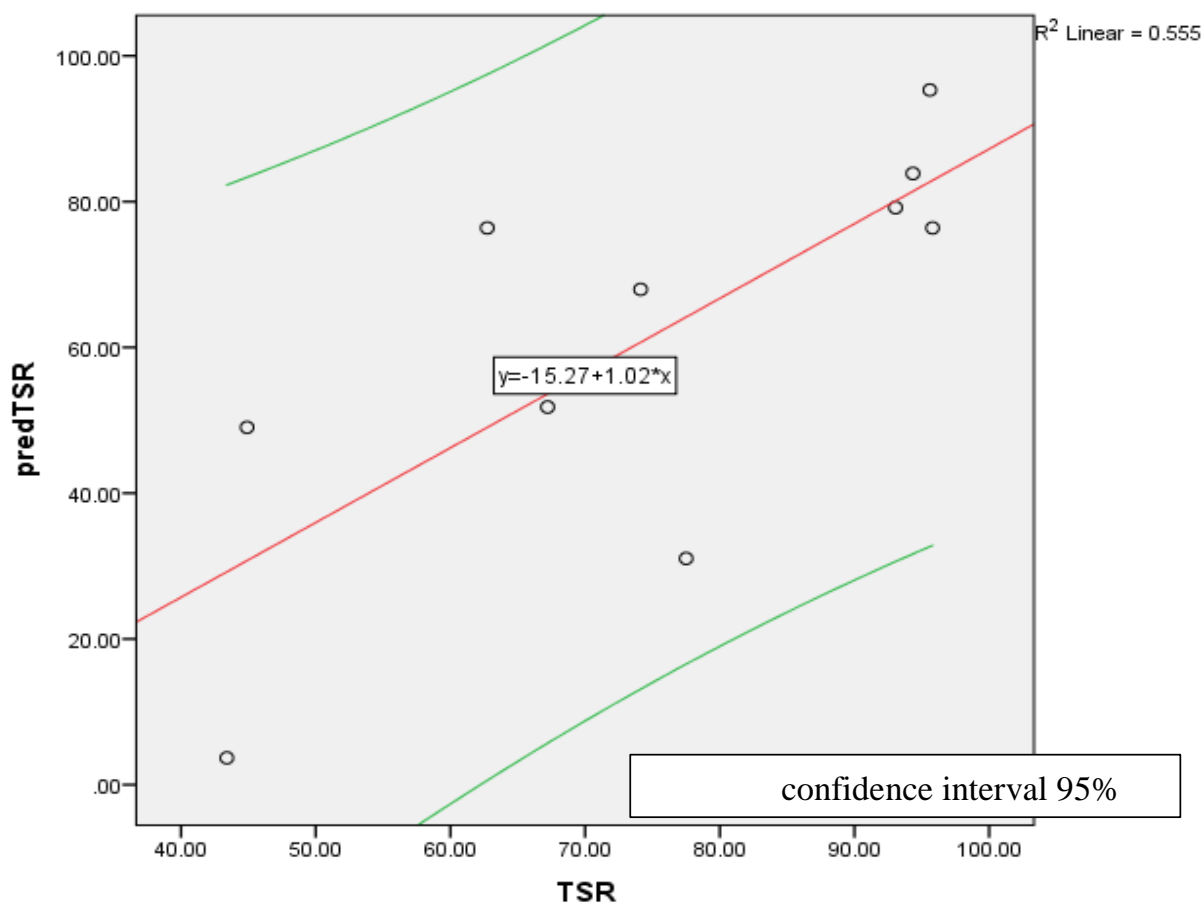

Figure 3comparisons between the experimental and predicted values of TSR.

\subsection{Building the Indirect tensile strength model.}

As mentioned previously the ITS was selected to build a model from many Mechanical parameters. This selection is established on the believe that it is the most important mechanical character. Modeling ITS to filler type, binder content, and polymer content was conducted. Many models were tried (linear, multiple and nonlinear models). It was observed that all linear models were failed to estimate accurate predicted values of ITS. Tables (15) demonstrated samples of the tried models, whereas low values of $\left(\mathrm{R}^{2}\right)$ are the predominant for both regression and model validation. It is worth mentioned that other testing parameters than $\mathrm{R}^{2}$ were used to test the validity of the models, but the values of $\mathrm{R}^{2}$ are only presented for simplification and prevent dilatation.

On the other hand, after many trials a nonlinear model was determined with reasonable accuracy. The analysis results of adopted nonlinear model are shown in Tables (16), (17), and (18). The model's analysis consists of the analysis of goodness fitting and variance for observed and predicted results. Figure (4) demonstrates the adequacy of model. The following can be recognized from the analysis process:

1. Table (16) explained the bivariate Pearson Correlation between variables. The same table shows that the independent variables have low to absent of correlation between each other, which is good for the accuracy of the model. 
2. Table (16) demonstrates that the polymer content has the most significant correlation to ITS, then filler type and lastly binder content.

3. Table (18) states that the MSE is low, which is good for the significant of the model.

4. Table (17) shows the parameter of the developed model and its limitation with Confidence Interval of $95 \%$.

5. Table (18) discloses that the sum of regression is higher that sum of residue which is sustained the significant of the model. While, from the same table, the high value of the R-Square $(0.820)$ indicates a perfect prediction, thus from this value a conclusion can draw that the developed model for ITS is acceptable.

6. Figure (4) indicates that acceptable scatter can recognize between predicted and observed operability values, furthermore, almost all value within the significant level boundaries.

Table 14 Trial Equations to Predict The Value of Indirect tensile strength.

\begin{tabular}{|c|c|c|}
\hline Types of equations & Models & $\boldsymbol{R}^{\mathbf{2}}$ \\
\hline Linear & $I T S=621.6+3.81 * s b s+22.6 * b c-11.57 * f t$ & 0.367 \\
\hline Linear & $I T S=555.02+3.93 * s b s$ & 0.303 \\
\hline Cubic & $I T S=145.8+55.8 * s b s-1.6 * s b s^{2}+0.16 * s b s^{3}$ & 0.489 \\
\hline Compound & $\ln I T S=539.3+1.007 * s b s$ & 0.244 \\
\hline Logarithmic & $\ln I T S=358.8+0+19 * \ln s b s$ & 0.297 \\
\hline Nonlinear & $I T S=568+0.029 * b c * s b s * f t$ & 0.29 \\
\hline Nonlinear & $I T S=713.2+3.95 * s b s-1.357 * b c * f t$ & 0.34 \\
\hline Nonlinear & $I T S=621.6+3.81 * s b s+22.6 * b c-11.6 * f t$ & 0.367 \\
\hline Nonlinear & $I T S=1092.18-7.59 * s b s-1.3 * b c-28.57 * f t+0.095$ & 0.405 \\
& $* s b s * b c * f t$ & \\
\hline
\end{tabular}

Table 15 correlation between ITS and variables.

\begin{tabular}{|c|c|c|c|c|c|}
\hline \multicolumn{6}{|c|}{ Correlations } \\
\hline & & $S B S$ & $B C$ & $F T$ & ITS \\
\hline \multirow[t]{3}{*}{$s b s$} & Pearson Correlation & 1 & .117 & -.039 & $.551 * *$ \\
\hline & Sig. (2-tailed) & & .491 & .818 & .000 \\
\hline & No. & 37 & 37 & 37 & 37 \\
\hline \multirow[t]{3}{*}{$b c$} & Pearson Correlation & .117 & 1 & -.089 & .152 \\
\hline & Sig. (2-tailed) & .491 & & .601 & .371 \\
\hline & No. & 37 & 37 & 37 & 37 \\
\hline \multirow[t]{3}{*}{$f t$} & Pearson Correlation & -.039 & -.089 & 1 & -.264 \\
\hline & Sig. (2-tailed) & .818 & .601 & & .114 \\
\hline & No. & 37 & 37 & 37 & 37 \\
\hline \multirow[t]{3}{*}{ ITS } & Pearson Correlation & $.551 * *$ & .152 & -.264 & 1 \\
\hline & Sig. (2-tailed) & .000 & .371 & .114 & \\
\hline & No. & 37 & 37 & 37 & 37 \\
\hline
\end{tabular}

Table 16 Nonlinear ITS modeling

\begin{tabular}{|c|c|c|c|c|}
\hline $\begin{array}{c}\text { Developed } \\
\text { model }\end{array}$ & \multicolumn{4}{|c|}{$I T S=c 1+c 2 * s b s-c 3 * s b s^{2}+c 4 * s b s^{3}+c 5 * b c-c 6 * b c^{2}-c 7 * f t$} \\
\hline \multicolumn{5}{|c|}{ Parameter Estim. } \\
\hline \multirow[b]{2}{*}{ Parameter } & \multirow[b]{2}{*}{ Estim. } & \multirow[b]{2}{*}{ Std. Err. } & \multicolumn{2}{|c|}{ 95\% Confidence Interval } \\
\hline & & & Lower Bound. & Upper Bound. \\
\hline$c 1$ & -7647.534 & 1145.557 & -9987.073 & -5307.994 \\
\hline$c 2$ & 34.169 & 9.829 & 14.096 & 54.242 \\
\hline$c 3$ & 1.092 & .317 & .445 & 1.740 \\
\hline$c 4$ & .011 & .003 & .005 & .017 \\
\hline$c 5$ & 2607.087 & 370.707 & 1850.003 & 3364.170 \\
\hline$c 6$ & 209.286 & 29.821 & 148.383 & 270.189 \\
\hline$c 7$ & 4.226 & 3.959 & -3.860 & 12.312 \\
\hline
\end{tabular}


Table 17 ANOVA for ITS modeling

\begin{tabular}{|c|c|c|c|}
\hline \multicolumn{5}{|c|}{ ANOVAa } \\
\hline Source & Sum of Squares & $d f$ & Mean Squares \\
\hline Regression & 16602904.820 & 7 & 2371843.545 \\
\hline Residual & 93367.856 & 30 & 3112.262 \\
\hline Uncorrected Total & 16696272.670 & 37 & \\
\hline Corrected Total & 518335.159 & 36 & \\
\hline \multicolumn{4}{|c|}{ Dep. variable: ITS } \\
\hline \multicolumn{4}{|c|}{ R squared $=1$ - (Residual Sum of Squares)/(Corrected Sum of Squares) $=.820}$. \\
\hline
\end{tabular}

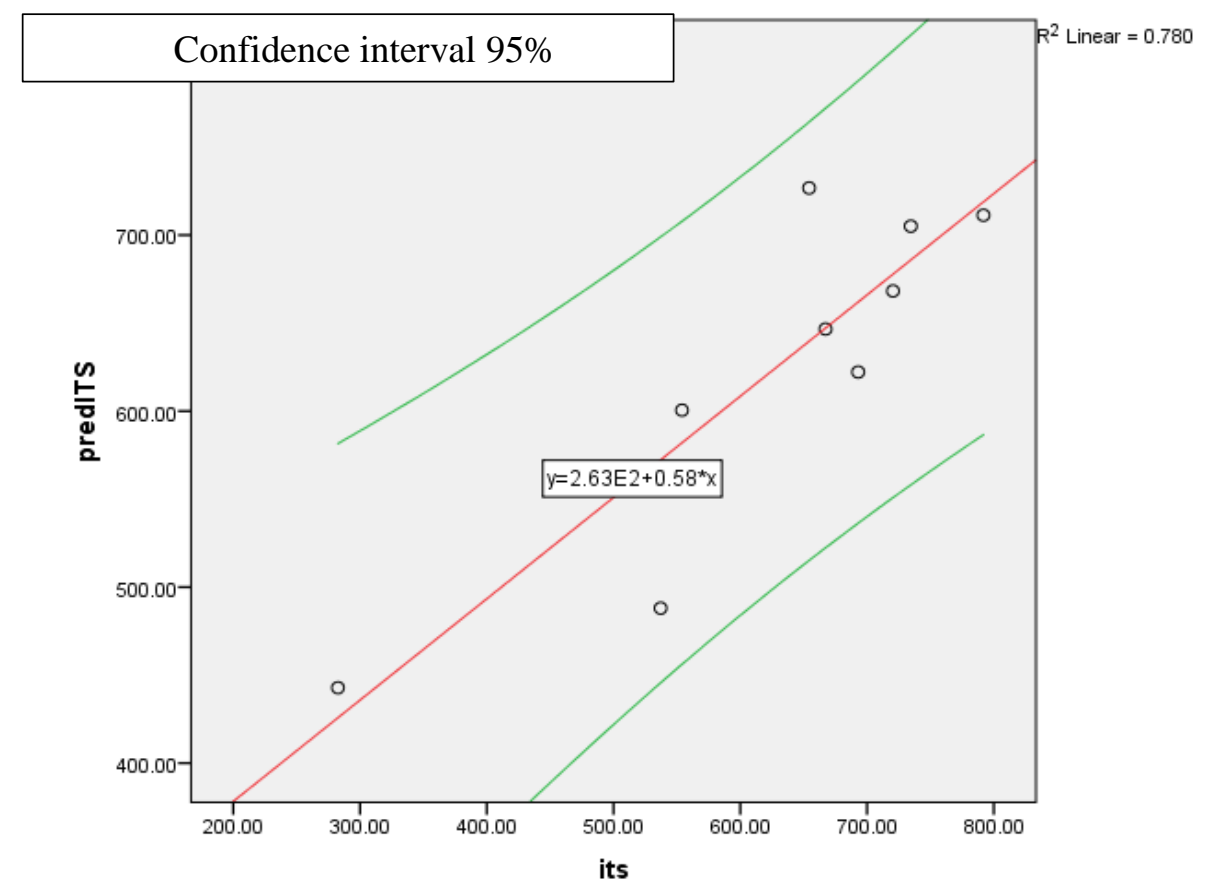

Figure 4comparisons between the experimental and predicted values of ITS.

\section{Conclusion.}

From the statistical analysis of this research study, the following can be concluded:

1. General well-known linear and nonlinear model offered by available software could not represent the resulted values of mechanical, volumetric and durability properties in acceptable models.

2. Modeling the OGFC volumetric, mechanical, and durability characteristics with reference to mix design inputs is achievable and satisfactory in terms of prediction and the significant of input parameters with more complicated multi-variable non-liner models.

3. Permeability model is proven to be predictive from filler type, polymer content, and binder content. At the same time and within models' boundaries, the filler type has the most significant correlation to permeability, then binder content and lastly polymer content.

4. Moisture sensitivity model is proven to be predictive from filler type, polymer content, and binder content. At the same time and within models' boundaries, filler type has the most significant correlation to TSR, then polymer content and lastly binder content

5. ITS model is proven to be predictive from filler type, polymer content, and binder content. Simultaneously and within models' boundaries, polymer content has the most significant correlation to ITS, then filler type and lastly binder content.

\section{CONFLICT OF INTERESTS.}

- There are no conflicts of interest. 


\section{References:}

[1] A. E. Alvarez, E. Mahmoud, A. E. Martin, E. Masad, and C. Estakhri, "Stone-on-stone contact of permeable friction course mixtures," J. Mater. Civ. Eng., vol. 22, no. 11, pp. 1129-1138, 2010.

[2] V. S. Arrieta and J. E. C. Maquilón, "Resistance to Degradation or Cohesion Loss in Cantabro Test on Specimens of Porous Asphalt Friction Courses," Procedia - Soc. Behav. Sci., vol. 162, pp. 290299, Dec. 2014.

[3] K.-W. Liu, A. E. Alvarez, A. E. Martin, T. Dossey, A. Smit, and C. K. Estakhri, "Synthesis of Current Research on Permeable Friction Courses: Performance, Design, Construction, and Maintenance," Texas Dep. Transp. Fedral Highw. Adm. Austin, Texas, 2010.

[4] J. W. Button, E. G. Fernando, and D. R. Middleton, "Synthesis of pavement issues related to highspeed corridors," 2004.

[5] M. Hossain, C. Manandhar, and C. Hobson, "Noise Reducing Porous Asphalt Pavement," 2010.

[6] C. Pagotto, M. Legret, and P. Le Cloirec, "Comparison of the hydraulic behaviour and the quality of highway runoff water according to the type of pavement," Water Res., vol. 34, no. 18, pp. 44464454, 2000 .

[7] M. E. Barrett, "Effects of a permeable friction course on highway runoff," J. Irrig. Drain. Eng., vol. 134, no. 5, pp. 646-651, 2008.

[8] R. M. Roseen, T. P. Ballestero, J. J. Houle, J. F. Briggs, and K. M. Houle, "Water Quality and Hydrologic Performance of a Porous Asphalt Pavement as a Storm-Water Treatment Strategy in a Cold Climate," J. Environ. Eng., vol. 138, no. 1, pp. 81-89, 2012.

[9] A. E. Alvarez, A. E. Martin, C. K. Estakhri, J. W. Button, C. J. Glover, and S. H. Jung, "Synthesis of current practice on the design, construction, and maintenance of porous friction courses," 2006.

[10]J. Chen, C. Yao, H. Wang, Y. Ding, and T. Xu, "Expansion and contraction of clogged open graded friction course exposed to freeze-thaw cycles and degradation of mechanical performance," Constr. Build. Mater., vol. 182, pp. 167-177, 2018.

[11]X. Chen, H. Zhu, Q. Dong, and B. Huang, "Case study: performance effectiveness and cost-benefit analyses of open-graded friction course pavements in Tennessee," Int. J. Pavement Eng., vol. 18, no. 11, pp. 957-970, Nov. 2017.

[12]Y. Wang, Z. Leng, and G. Wang, "Structural contribution of open-graded friction course mixes in mechanistic-empirical pavement design," Int. J. Pavement Eng., vol. 15, no. 8, pp. 731-741, 2014.

[13]M. A. Hernandez-Saenz, S. Caro, E. Arámbula-Mercado, and A. Epps Martin, "Mix design, performance and maintenance of Permeable Friction Courses (PFC) in the United States: State of the Art," Constr. Build. Mater., vol. 111, pp. 358-367, May 2016.

[14]A. E. Alvarez, A. Epps-Martin, C. Estakhri, and R. Izzo, "Evaluation of durability tests for permeable friction course mixtures," Int. J. Pavement Eng., vol. 11, no. 1, pp. 49-60, Feb. 2010.

[15]P. E. Y. Wang, Y. Wen, K. Zhao, D. Chong, and A. S. T. Wong, "Evolution and locational variation of asphalt binder aging in long-life hot-mix asphalt pavements," Constr. Build. Mater., vol. 68, pp. $172-182,2014$.

[16]Wang, Yuhong, Y. Wen, K. Zhao, D. Chong, and J. Wei, "Connections between the rheological and chemical properties of long-term aged asphalt binders," J. Mater. Civ. Eng., vol. 27, no. 9, p. 4014248, 2014.

[17]J. Rodriguez-Hernandez, V. C. Andrés-Valeri, M. A. Calzada-Pérez, ángel Vega-Zamanillo, and D. Castro-Fresno, "Study of the raveling resistance of porous asphalt pavements used in sustainable drainage systems affected by hydrocarbon spills," Sustain., vol. 7, no. 12, pp. 16226-16236, 2015.

[18]L. A. Cooley, B. U. C. O. D. Ennis, and I. Nc, "Construction and Maintenance Practices for Permeable Friction Courses," 2009. 
[19]Kandhal, "design, construction, and maintenance of open-graded asphalt friction courses.information series 115, National Asphalt Pavement Association,” 2002.

[20]G. Huber, "Performance survey on open-graded friction course mixes," Transportation Research Board, 2000.

[21]M. M. A. A. A. M. M. F. C. Van De Ven, "Performance Modelling of Porous Asphalt Concrete using Artificial Intelligence,” Road Mater. Pavement Des., pp. 263-280, 2009.

[22]L. T. Mo, M. Huurman, S. P. Wu, and A. A. A. Molenaar, "Investigation into stress states in porous asphalt concrete on the basis of FE-modelling," Finite Elem. Anal. Des., vol. 43, no. 4, pp. 333-343, 2007.

[23]L. Mo, M. Huurman, S. Wu, and A. A. A. Molenaar, "Mortar fatigue model for meso-mechanistic mixture design of ravelling resistant porous asphalt concrete," Mater. Struct., vol. 47, no. 6, pp. 947961, Jun. 2014

[24]ASTM, "C 127 - 04 StandardStandard Test Method for Density, Relative Density (Specific Gravity), and Absorption," Am. Soc. Test. Mater., no. August, pp. 2-7, 2012.

[25]ASTM, "C131 Resistance to Degradation of Small-Size Coarse Aggregate by Abrasion and Impact in the Los Angeles Machine," vol. 04, pp. 4-7, 2003.

[26]ASTM, "D5821 - 13Standard Test Method for determining the percentage of fractured particles in coarse aggregate," Annu. B. Am. Soc. Test. Mater. ASTM Stand., vol. i, pp. 1-6, 2014.

[27]ASTM, "D946/D946M - 09Standard Specification for Penetration-Graded Asphalt Binder for Use in Pavement," vol. i, pp. 7-8, 2017.

[28]ASTM, "D5-05a Standard Test Method for Penetration of Bituminous Materials," vol. i, pp. 3-6, 2005.

[29]J. Read and D. Whiteoak, The Shell bitumen handbook. 2003.

[30]ASTM, “ASTM-D5 Standard Test Method for Penetration of Bituminous Materials,” vol. i, pp. 36, 2005.

[31]ASTM, "D1754/D1754M - 09 (Reapproved 2014) Standard Test Method for Effects of Heat and Air on Asphaltic Materials ( Thin-Film Oven Test)," vol. 97, no. Reapproved, pp. 1-7, 2014.

[32]ASTM, "D 7064-08 Standard Practice for Open-Graded Friction Course (OGFC) Mix Design," Annu. B. Am. Soc. Test. Mater. ASTM Stand., vol. 08, no. Reapproved 2013, pp. 1-7, 2013.

[33]AASHTO, "Determining the creep compliance and strength of HMA.” p. 16, 2003. 


\title{
خصائص النماذج الاحصائية للخلطات النفاذة الاحتكاكية
}

\author{
علا عباس شاكر فالح شاكر \\ قسم الهيسة المدنية، كلية الهنسة، جامعة كربلاء، كربلاء، العراق
}

aljawadola@yahoo.com_s.f.al-busaltan@uokerbala.edu.iq

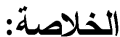

الطبقات النفاذة الاحتكاكية هي نوع خاص من الخطات الني تستعمل كطبقة نهائية فوق سطح الخلطات الاعتيادية حيث ازداد

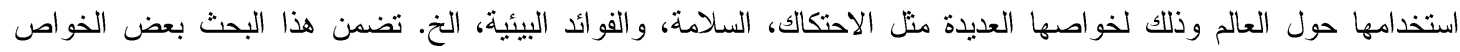

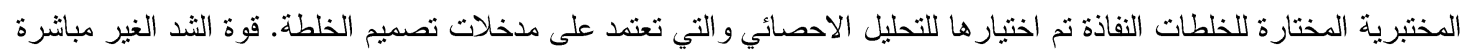

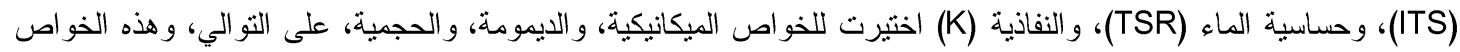

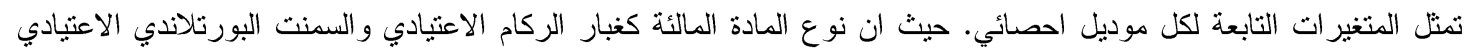
(CMF, OPC) الموديلات الاحصائية الدتولدة توفر اداة تتبا قابلة للنحقق حيث كانت قيم RC هي

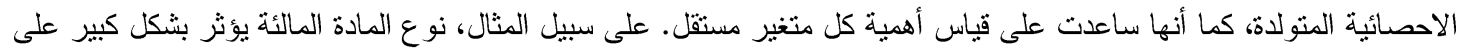

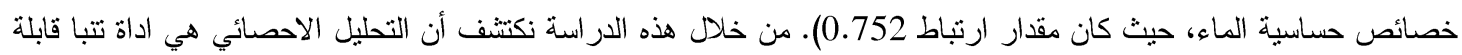
النحقق لوصف خصائص و أداء الخلطات النفاذة الاحتكاكية من حيث الخصائص الحجمية و الميكانيكية والينانة. الكلمات الدالة: خرسانة اسفلتية، الطبقات النفاذة، الاسفلت المعدل مع البوليمر، التحليل الاحصائي. 